\title{
Twelve Tips for Just in Time Teaching of Communication Skills for Difficult Conversations in the Clinical Setting
}

\author{
Laura Hinkle, MD
}

Department of Medicine, Division of Pulmonary and Critical Care Medicine, Indiana University School of Medicine, Indianapolis, United States of America

Lyle Fettig, MD

Department of Medicine, Indiana University School of Medicine, Indianapolis, United States of America

W. Graham Carlos, MD, MSCR

Department of Medicine, Division of Pulmonary and Critical Care Medicine, Indiana University School of Medicine, Indianapolis, United States of America

Gabriel Bosslet, MD, MA

Department of Medicine, Division of Pulmonary and Critical Care Medicine, Indiana University School of Medicine, Indianapolis, United States of America

Corresponding Author:

Laura Hinkle, MD

1120 Michigan Street

Gatch Hall, Suite 260

Indianapolis, IN 46202

ljhinkle@iu.edu

This is the author's manuscript of the article published in final edited form as: 
LAURA HINKLE, MD, is a Pulmonary and Critical Care Medicine fellow in her final year of training at Indiana University, Indianapolis, IN. Her interests include medical education, particularly in the areas of communication and interprofessional practice.

LYLE FETTIG, MD, is an Assistant Professor of Clinical Medicine and Director of the Hospice and Palliative Medicine Fellowship at Indiana University, Indianapolis, IN. His interests include teaching effective communication techniques to improve the care of seriously ill patients.

W. GRAHAM CARLOS, MD, MSCR, is an Associate Professor of Clinical Medicine and Assistant Dean for Medical Student Education at Indiana University, Indianapolis, IN. His interests include development of innovative methods of teaching to engage learners in the classroom and clinical settings.

GABRIEL BOSSLET, MD, MA, is an Associate Professor of Clinical Medicine and Program Director for the Pulmonary and Critical Care Medicine fellowship at Indiana University, Indianapolis, IN. His interests include teaching effective communication techniques for delivering bad news and developing innovative ways of more objectively evaluating fellowship candidates. 


\title{
Twelve Tips for Just in Time Teaching of Communication Skills for Difficult Conversations in the Clinical Setting
}

\author{
The ability to communicate well with patients and other members of the \\ healthcare team is a vital skill for physicians to have, but one that is often not \\ emphasized in medical education. Learners of all levels can obtain and develop \\ good communication skills regardless of their natural ability in this area, and the \\ clinical setting represents an underutilized resource to accomplish this task. With \\ this in mind, we have reviewed the growing body of literature on the subject and \\ organized our findings into twelve tips to help educators capitalize on these \\ missed opportunities. While our emphasis is helping learners with difficult \\ discussions, these tips can be easily adapted to any other clinical encounter \\ requiring clear communication. Teaching effective communication skills in the \\ clinical setting requires some extra time, but the steps outlined should not take \\ more than a few minutes to complete. Taking the time to develop these skills in \\ our learners will make a significant difference not only their lives but also their \\ patients and their families.
}

Keywords: feedback; communication skills; clinical; general; medicine

\section{Introduction}

The ability to communicate well with patients and other healthcare team members is a crucial part of being a physician, yet it has not been traditionally emphasized in medical education curricula (Epner and Baile 2014, Fraser et al. 2001, Modi et al. 2016, Roze des Ordons et al. 2016, Sanson-Fisher and Cockburn 1997). This skills gap becomes most apparent when learners are faced with the difficult task of delivering bad news, disclosing a medical error, or initiating end-of-life discussions with patients and families (Orlander et al. 2002). Physicians often lack needed skills to effectively and empathically communicate key information patients and families need to make the difficult decisions surrounding care near the end-of-life (Sharma et al. 2014). Patients and families rate communication skills as one of the most important skills for a physician (Curtis et al. 2002), and patient-centered communication in these instances 
not only improves quality of care and patient satisfaction, but may also reduce burnout among providers (Epner and Baile 2014).

The importance of providing learners with better communication skills training is recognized by accrediting bodies who mandate that students should have end-of-life discussion training during their undergraduate medical education (Education 2015). These types of conversations can be stressful for all physicians, but are especially so for students who report high levels of stress even when breaking bad news to simulated patients (Hulsman et al. 2010, Romotzky et al. 2015, Schillerstrom et al. 2012). Many students complete their undergraduate medical education feeling unprepared to engage in these conversations (Fraser, Kutner and Pfeifer 2001). Opportunities for learners to engage in these discussions abound on clinical rotations, yet one study found that only $17 \%$ of medical school faculty reported teaching aspects of end-of-life care to their trainees over the previous year (Benson 2016). Bedside teaching of communication skills in these difficult settings are an area where significant impact in trainee education can be achieved. While comprehensive faculty development in this area is beyond the scope of this work, our hope is that these twelve tips for teaching difficult communication skills at the bedside will provide an initial framework for educators to take advantage of these opportunities.

\section{Twelve Tips}

Tip 1. Recognize that communication skills can be taught and developed in the clinical setting.

Learners can develop communication skills, regardless of their degree of natural ability (Back 2007, Carvalho 2014). An effective strategy is to combine traditional lecturebased teaching with opportunities to observe skilled communicators and then practice these skills in an observed setting with feedback (Carvalho 2014, Epner and Baile 
2014). Clinical rotations are an underutilized venue for directly observed practice and feedback, and should be capitalized upon whenever possible (Janicik 2007, Vu et al. 2015). These represent high yield opportunities for adult learners because they present immediate and problem centered tasks (Kaufman 2003). Even novice learners can benefit from appropriate involvement in difficult conversations, as this provides experience not available elsewhere in the curriculum.

\section{Tip 2. Assess your learner's level of skill and comfort with communication.}

The learner's role should be commensurate with his or her skill and confidence level. Just as one would not expect a learner who had never observed a procedure to be able to perform it, learners should not be expected to independently lead difficult conversations with no previous practical or observational experience. Unfortunately, this is often exactly what happens. A survey of residents found that most had their first experience delivering bad news as a student or during intern year. These conversations often occurred without a more senior person in the room and most learners did not feel prepared to engage in the conversation. (Orlander, Fincke, Hermanns and Johnson 2002).

Determination of your learner's communication skills is an ongoing process. Valuable insight can be obtained through direct observation of routine communication during bedside rounds, and by asking a learner about their past experiences with challenging conversations and perceived roadblocks. Before a potentially difficult conversation with a patient or family, you can explore anticipated challenges with your learner and their comfort level with the situation.

\section{Tip 3. Assess your learner's understanding of the clinical situation.}

Does your learner understand what is going on clinically, including prognostic implications and treatment options? Patients and families need accurate information in 
order to make informed healthcare decisions and most will want both qualitative and quantitative information about prognosis (Heyland et al. 2009, Kaplowitz et al. 2002, Walczak et al. 2014). Questions surrounding these topics are likely to arise during the discussion and it is important that the learner be prepared to answer them if he or she will be leading the conversation. (Kaplowitz, Campo and Chiu 2002). Assessing this aspect of the learner's understanding is an important consideration prior to deciding what their role will be.

\section{Tip 4. Align the learner's educational needs and assigned role in the conversation}

Matching the skills and comfort level of the learner with their educational needs and the anticipated difficulty level of the conversation is vitally important. If it is anticipated to be a volatile discussion with significant conflict, a relatively novice learner may benefit most by focused observation, while a seasoned learner who knows the patient well would get maximal benefit from leading the conversation and getting feedback on their skills. In one study, nearly all learners who either observed a more experienced person leading the conversation or led discussions with a more senior person observing, found the experience to be valuable (Orlander, Fincke, Hermanns and Johnson 2002), so either role can be beneficial. Another good option may be to invite learners to lead a specific part of the discussion. For example, a learner who wishes to work on explaining a complex condition in clear and concise terms could provide an update on the clinical course while a more senior person leads discussion about treatment options and goals of care.

If the learner is going to be conducting the meeting, it is a good idea to have a pre-planned "help cue.” Cues might include eye contact with a nod or a verbal question that will signal you that the learner feels overwhelmed and needs your help.

Tip 5. Review the meeting agenda with your learner. 
Once the learner's role has been established, the goals for the meeting should be discussed, emphasizing establishment of the patient and family's agenda for the meeting. Determination of the message for the family is crucial, and asking "What is one message that you want the family to take away from this conversation?” can be a helpful way to focus the learner's language.

This is also a good time to review the SPIKES mnemonic that may help your learner frame the discussion (Baile et al. 2000).

- $\quad$ Setting - find a location that is quiet and private

- Perception - ask what the patient or family understands about what is happening

- Invitation - ask for permission to share information

- Knowledge - provide information simply

- Empathy - acknowledge and respond to emotions

- Summary - review what has been said, decisions that have been made, and next steps

Something to consider with your learner as you talk about framing the discussion are individual patient and family characteristics that will significantly impact how you approach the conversation. It is important to assess the spiritual needs of patients and their families because those finding comfort and support in religion and spirituality may appreciate having a member of the clergy present during a difficult discussion (Wall et al. 2007). Cultural differences are another factor that can significantly alter the approach to the discussion. A study in France found that over half of family members did not wish to participate in decision making and if required to do so, these individuals had higher rates of post-traumatic stress disorder, anxiety, and depression (Azoulay et 
al. 2005). For those who value autonomy highly, the opposite is true (Anderson et al. 2009). Finally, while having extended family present is often helpful for all involved, the complexity of the discussion increases as family conflict, patients' wishes to keep certain information private, and concern for protection of patient autonomy all come into play (Laidsaar-Powell et al. 2013).

\section{Tip 6. Discuss individualized, skill-based learning goals.}

Identifying specific learning goals prior to the encounter increases the likelihood that your learner will focus on and demonstrate the desired behavior or technique and helps you provide focused feedback (Fryer-Edwards n.d., Kaufman 2003). Learners benefit most if they identify their own learning goals, even if they will be observing. However, they may need guidance to formulate well-defined, skill-based goals. For example, they may say, “I just need to communicate better. I don’t know what to say when family members are upset.” This learner has successfully identified a weakness, lack of skill in addressing emotions, but was unable to define it as such.

Other learners may have difficulty identifying goals that are achievable at their current skill level or narrowing their focus on one or two things that can be accomplished in the current encounter. Helping the learner better delineate specific, achievable goals and the communication skills needed to accomplish them will increase the likelihood of success.

\section{Tip 7. Review communication skills relevant to the learner's goal.}

Both the agenda of the encounter and the self-directed learning goals should be used to guide which techniques are reviewed with the learner. It is important that the skills emphasized here are titrated to the learner's skill level. 
For early learners it is probably reasonable to discuss very basic communication skills such as sitting at eye level, allowing everyone in the room an opportunity to introduce themselves, and avoiding jargon when speaking. Once the learner has developed these skills, additional skills may be introduced. These include "I wish" statements and the effective use of silence. I wish statements such as, "I wish we could do something to make your father well,” provide a simple way of demonstrating empathy for and recognition of what the patient and family are facing. Periods of silence in the discussion allow patients and families opportunity for an increased voice in the discussion and lead to improved patient and family satisfaction (Epner and Baile 2014, McDonagh et al. 2004).

For the more advanced learner, recognizing emotion and expressing empathy should be discussed. The NURSE mnemonic outlines several effective strategies for expressing empathy in difficult communication. (Baile, Buckman, Lenzi, Glober, Beale and Kudelka 2000).

- $\quad$ Name - name the identified emotion

- $\quad$ Understand - verbalize understanding of what has been said

- $\quad$ Respect - express respect for what the patient or family has done

- $\quad$ Support - assure the patient or family they will not be abandoned

- $\quad$ Explore - ask them to elaborate about what they are saying

Explicitly reviewing the relevant communication skills is an important step. Even if your learner will primarily observe, you will want them to watch for how specific skills are used in the conversation: "You said you are curious about naming emotions. I will attempt to do that at least once.” It is important to focus on only 1 or 2 skills during the session to avoid overloading the learner. 
Tip 8. Set your learner up for success by setting the stage for the encounter with the patient and family.

In our experience, having a more senior person in the room sometimes creates a challenge as patients and families often look to the person they identify as being "in charge” for answers, undermining the learner's ability to lead the conversation. To mitigate this, the learner's role in the discussion should be made clear at the beginning, with reassurances that you are available if needed (Back 2007). This is often best accomplished during introductions. "I am Dr. Smith, the physician-in-charge, and Dr. Jones is a training physician working with me who has cared for your father throughout his hospitalization. If it is alright with you, I would like her to lead this discussion and I will remain here and available if needed.” This statement makes roles clear while giving the family a chance to "opt out" of having a trainee lead the meeting if desired.

\section{Tip 9. Be an active observer.}

Make notes during the encounter. Pay attention not only to what is said, but body language, tone, and emotions of the learner, patient, and family members, particularly as these relate to the learning goals. Be as specific as possible, watching for how the learner uses the skill they selected prior to the conversation. This will allow you to give effective feedback later on as you will be able to discuss how the patient and family are affected not only by what the learner says, but how they say it (Back 2007, FryerEdwards n.d.). If your learner is going to be an observer, instruct him or her to make notes in this same manner to maximize their learning from the experience (Back 2007).

Tip 10. Try not to interrupt, but be prepared to step in if necessary.

If the plan was to let the learner lead the discussion, let them proceed unless they signal you for help. This is often the most difficult part of observing a learner in this setting! 
Even if the approach they take is not exactly how you would do it, they need this opportunity to learn. However, it is important to balance this learning opportunity with your obligation to patients and their families. If you are concerned that information needed to make important decisions is not being adequately covered, you can often add a few comments at the end to ensure this need is met. A more difficult situation arises when the patient or family is becoming distressed and the learner does not recognize it, or if the meeting is going off the rails altogether. If this is the case, you need to step in to prevent the situation from spiralling out of control (Back 2007). A good way to do this is to simply invite yourself into the discussion by saying, "Would it be ok if I added something here?” This creates an opening to step in without undermining your learner and allows you to either take control of the remainder of the discussion or re-introduce the learner into the discussion if appropriate. Both learners and teachers are highly invested in the conversation's success, and these techniques can help balance the need for learner practice with the teacher's responsibility to the patient.

\section{Tip 11. Debrief with your learner as soon as possible after the encounter.}

Reflection and specific feedback are arguably the most important part of bedside communication skills teaching. It allows the learner to incorporate what transpired into the fabric of their personal experience and promotes accountability (Branch and Paranjape 2002, French et al. 2015). Learners may need to talk about the impact this experience had on them before being able to process any feedback you provide, so giving feedback in a quiet location with privacy is ideal (Fryer-Edwards n.d.).

Specific feedback focuses on communication skills, not style (Table 1). The Ask-Tell-Ask model provides an effective framework for learner centered feedback to reinforce good communication skills while identifying those that could be improved upon. (French, Colbert, Pien, Dannefer and Taylor 2015). Ask your learner to reflect 
on the encounter and provide their self-assessment. Next, Tell the learner of your own observations, including a reflection on their self-assessment. Finally, Ask the learner to reflect on the feedback and commit to a future learning goal (Tip 12).

Start by asking “What went well?” Some learners may struggle to remember what they said or did and others may feel things went very well when you believe they did not. In either case, ask about specific moments in the conversation, relating to the learning goal. For example, if the goal was to respond to emotions effectively, you could say, "When Mrs. B started to cry, you said 'I see that this is upsetting to you.' Do you recall what she did when you said that?” The learner may recall Mrs. B spoke more about why the situation was upsetting, providing greater insight into her perspective. If the learner cannot recall this, you can point out her response. If the learner failed to acknowledge the expressed emotion, you could say, "When you told Mrs. B. about the diagnosis, she started to cry. How could you have responded to that?” Exploration of key moments in the conversation reinforces the idea that use of specific communication skills can lead to observable patient responses. As mentioned above, taking notes is important to help you provide this kind of detailed feedback.

Next, ask the learner to describe challenges that arose during the conversation. Center your feedback on these, even if you observed other challenges as learners are generally more open to feedback about self-identified challenges. Again, use your notes to help focus on specific points in the dialogue relating to the challenge. For example, if a learner says Mr. S seemed to "shut down” part way through the conversation, but cannot remember when, you can refer to notes and say, "When you told him the antibiotics didn’t work, Mr. S became tearful and looked away. I noticed that you continued talking about medical issues, but he seemed too distracted to listen.” If a learner cannot identify a challenge, it can help to draw attention to a family member's 
response. “When you told Mr. S the antibiotics didn’t work; how did his daughter respond?” This provides an opportunity for feedback to the learner who has not been attending to the family's response. Prompt the learner to come up with 1-2 alternative responses and then provide your own feedback on these.

For learners who are observers, Ask-Tell-Ask can likewise be used to elicit their observations about your communication skills and challenges. For example, they may have been assigned the task of observing for patient emotions and how you responded to them. You may wish to model self-reflection here by talking about the challenges you encountered in the conversation, why you chose to say what you did, and what might be done differently in the future (Back 2007, French, Colbert, Pien, Dannefer and Taylor 2015, Fryer-Edwards n.d.).

\section{Tip 12. Help your learner develop an action plan to further improve skills.}

The final “Ask” in the Ask-Tell-Ask model is to Ask your learner about a lesson they will take forward with them in practice, "What's one thing you might do differently in the future?” This allows you to determine if your feedback was heard as intended and correct any misconceptions. Have your learner pick one area to improve upon and help them create a plan to achieve this moving forward. Don't try to fix everything! Allowing your learner to choose one skill to improve and then making a plan to accomplish this is most likely to achieve the desired outcome of overall improvement (Back 2007, French, Colbert, Pien, Dannefer and Taylor 2015, Fryer-Edwards n.d.) Keep note of these goals so you can revisit them when a similar situation arises in the future.

\section{Conclusion}

Bedside interactions with patients and families on clinical rotations provide an invaluable resource for teaching our learners to be effective and empathic communicators. Allowing time to plan the discussion and discuss goals and roles with 
your learner prior to the encounter and provide feedback afterwards is essential to maximize the impact of the experience. Obviously, teaching communication skills effectively requires an educator to have these skills themselves. These twelve tips provide an initial framework for communication skills teaching, but we encourage readers to pursue additional opportunities to develop teaching skills in this area. Taking advantage of opportunities to teach effective communication skills in the clinical setting requires time, but the steps outlined should not take more than a few minutes, and can make a significant difference in the lives of our learners, patients, and their families.

\section{Declaration of Interest}

The authors report no conflicts of interest. The authors alone are responsible for the content and writing of the article.

\section{References}

Anderson WG, Arnold RM, Angus DC, Bryce CL. 2009. Passive decision-making preference is associated with anxiety and depression in relatives of patients in the intensive care unit. Journal of critical care. Jun;24:249-254.

Azoulay E, Pochard F, Kentish-Barnes N, Chevret S, Aboab J, Adrie C, Annane D, Bleichner G, Bollaert PE, Darmon M, et al. 2005. Risk of post-traumatic stress symptoms in family members of intensive care unit patients. Am J Respir Crit Care Med. May 01;171:987-994.

ONCOTALK Teach: A faculty development program Seattle, Washington: University of Washington. Available from

https://depts.washington.edu/oncotalk/Learning_Modules.pdf

Baile WF, Buckman R, Lenzi R, Glober G, Beale EA, Kudelka AP. 2000. SPIKES—a six-step protocol for delivering bad news: application to the patient with cancer. The oncologist.5:302-311.

Benson J. 2016. Having a Meaningful Conversation with Patients about the End of Life: Six Tips for Physicians. Minnesota medicine. Jan-Feb;99:36-38.

Branch WT, Jr., Paranjape A. 2002. Feedback and reflection: teaching methods for clinical settings. Academic medicine : journal of the Association of American Medical Colleges. Dec;77:1185-1188. 
Carvalho I, Pais VG, Silva FR, Martins R, Figueiredo-Braga M, Pedrosa R, Almeida SS, Correia L, Ribeiro-Silva R, Castro-Vale I, et al. 2014. Teaching communication skills in clinical settings: comparing two applications of a comprehensive program with standardized and real patients. BMC Med Educ. May 09;14:92.

Curtis JR, Engelberg RA, Wenrich MD, Nielsen EL, Shannon SE, Treece PD, Tonelli MR, Patrick DL, Robins LS, McGrath BB, et al. 2002. Studying communication about end-of-life care during the ICU family conference: development of a framework. Journal of critical care. Sep;17:147-160.

Functions and Structure of a Medical School. June 2015. Available from http://lcme.org/publications/ - Standards

Epner DE, Baile WF. 2014. Difficult conversations: teaching medical oncology trainees communication skills one hour at a time. Academic medicine : journal of the Association of American Medical Colleges. Apr;89:578-584.

Fraser HC, Kutner JS, Pfeifer MP. 2001. Senior medical students' perceptions of the adequacy of education on end-of-life issues. Journal of palliative medicine. Fall;4:337343.

French JC, Colbert CY, Pien LC, Dannefer EF, Taylor CA. 2015. Targeted Feedback in the Milestones Era: Utilization of the Ask-Tell-Ask Feedback Model to Promote Reflection and Self-Assessment. Journal of surgical education. Nov-Dec;72:e274-279.

Tough Talk: Helping Doctors Approach Difficult Conversations - A Toolbox for Medical Eduators Seattle Washington: University of Washington. Available from https://depts.washington.edu/toolbox/content.pdf

Heyland DK, Allan DE, Rocker G, Dodek P, Pichora D, Gafni A, Canadian Researchers at the End-of-Life N. 2009. Discussing prognosis with patients and their families near the end of life: impact on satisfaction with end-of-life care. Open Med. Jun 16;3:e101110 .

Hulsman RL, Pranger S, Koot S, Fabriek M, Karemaker JM, Smets EM. 2010. How stressful is doctor-patient communication? Physiological and psychological stress of medical students in simulated history taking and bad-news consultations. Int J Psychophysiol. Jul;77:26-34.

Janicik R, Kalet, A, Schwartz, M, Zabar, S, Lipkin, M. 2007. Using Bedside Rounds to Teach Communication Skills in the Internal Medicine Clerkship. Journal]; 12

Kaplowitz SA, Campo S, Chiu WT. 2002. Cancer patients' desires for communication of prognosis information. Health Commun.14:221-241.

Kaufman DM. 2003. Applying educational theory in practice. Bmj. Jan 25;326:213-216. 
Laidsaar-Powell RC, Butow PN, Bu S, Charles C, Gafni A, Lam WW, Jansen J, McCaffery KJ, Shepherd HL, Tattersall MH, et al. 2013. Physician-patient-companion communication and decision-making: a systematic review of triadic medical consultations. Patient Educ Couns. Apr;91:3-13.

McDonagh JR, Elliott TB, Engelberg RA, Treece PD, Shannon SE, Rubenfeld GD, Patrick DL, Curtis JR. 2004. Family satisfaction with family conferences about end-oflife care in the intensive care unit: increased proportion of family speech is associated with increased satisfaction. Crit Care Med. Jul;32:1484-1488.

Modi JN, Anshu, Chhatwal J, Gupta P, Singh T. 2016. Teaching and Assessing Communication Skills in Medical Undergraduate Training. Indian Pediatr. Jun 08;53:497-504.

Orlander JD, Fincke BG, Hermanns D, Johnson GA. 2002. Medical residents' first clearly remembered experiences of giving bad news. Journal of general internal medicine. Nov;17:825-831.

Romotzky V, Galushko M, Dusterdiek A, Obliers R, Albus C, Ostgathe C, Voltz R. 2015. "It's Not that Easy"--Medical Students' Fears and Barriers in End-of-Life Communication. J Cancer Educ. Jun;30:333-339.

Roze des Ordons AL, Lockyer J, Hartwick M, Sarti A, Ajjawi R. 2016. An exploration of contextual dimensions impacting goals of care conversations in postgraduate medical education. BMC palliative care. Mar 21;15:34.

Sanson-Fisher R, Cockburn J. 1997. Effective teaching of communication skills for medical practice: selecting an appropriate clinical context. Medical education. Jan;31:52-57.

Schillerstrom JE, Sanchez-Reilly S, O'Donnell L. 2012. Improving student comfort with death and dying discussions through facilitated family encounters. Academic psychiatry : the journal of the American Association of Directors of Psychiatric Residency Training and the Association for Academic Psychiatry. May 1;36:188-190.

Sharma RK, Jain N, Peswani N, Szmuilowicz E, Wayne DB, Cameron KA. 2014. Unpacking resident-led code status discussions: results from a mixed methods study. Journal of general internal medicine. May;29:750-757.

Vu TR, Angus SV, Aronowitz PB, Harrell HE, Levine MA, Carbo A, Whelton S, Ferris A, Appelbaum JS, McNeill DB, et al. 2015. The Internal Medicine Subinternship--Now More Important than Ever: A Joint CDIM-APDIM Position Paper. Journal of general internal medicine. Sep;30:1369-1375.

Walczak A, Butow PN, Clayton JM, Tattersall MH, Davidson PM, Young J, Epstein RM. 2014. Discussing prognosis and end-of-life care in the final year of life: a 
randomised controlled trial of a nurse-led communication support programme for patients and caregivers. BMJ Open. Jun 26;4:e005745.

Wall RJ, Engelberg RA, Gries CJ, Glavan B, Curtis JR. 2007. Spiritual care of families in the intensive care unit. Crit Care Med. Apr;35:1084-1090. 